\title{
B.T. Sue Atkins Receives an Honorary Doctorate from the University of Pretoria
}

On 5 September 2008, the degree of Doctor of Literature, Honoris Causa, was conferred on B.T. Sue Atkins by the University of Pretoria. The decision by the Council and the Senate to award her this degree was taken on the grounds of the following considerations as stated in the following commendatio read at the graduation ceremony.

Sue Atkins has been a professional lexicographer since 1966, first with Collins (now HarperCollins) Publishers where she was General Editor of the first 'modern' innovative English-French dictionary, the Collins-Robert EnglishFrench Dictionary, then as Lexicographic Adviser to Oxford University Press, where she pioneered an effective methodology for the creation of bilingual dictionaries from corpus data, resulting in the Oxford-Hachette English-French Dictionary. She is currently Lexicographic Adviser to the FrameNet project at the International Computer Science Institute, Berkeley, California, and a member of the Advisory Board of the American National Corpus, and the International Journal of Lexicography.

In 2000, she was awarded an honorary D.Litt. by the University of Brighton, United Kingdom, for services to lexicography and linguistics, national and international. In 2002, she received a festschrift published by the European Association for Lexicography (EURALEX) to mark her contribution to international lexicography, and was made an Honorary Life Member of EURALEX, of which she is a past President.

She has organized and taught at many professional and academic training courses and workshops in lexicography, and held lexicographic consultancies with a number of prestigious research institutions. She has participated in important national and international research projects in the field of computational lexicography, and originated the idea of the British National Corpus.

Her main focus includes the lexical analysis of corpus data, and in particular the use of linguistic theory as basis for a systematic description of the language; designing databases to store lexicographic data for use by human lexicographers and computer lexicons; applying such databases in the creation of monolingual and bilingual dictionaries; the training of lexicographers; and the study of how dictionaries are actually used.

Sue Atkins presented more than 40 papers and presentations and is author or co-author of numerous publications of which The Oxford Guide to Practical Lexicography (2008) in cooperation with Michael Rundell is the latest. 
Her influence in the lexicographic world is described as follows in the foreword to Lexicography and Natural Language Processing: A Festschrift in Honor of B.T.S. Atkins (2002): 'Sue Atkins has not only inspired generations of lexicographers, but has also played a crucial role in developing links between the practical world of dictionary-making and the research communities of linguistics and natural language processing.'

With her workshops SALEX '97 (hosted by Rhodes University, Grahamstown) and AFRILEX-SALEX '98 (hosted by the University of Pretoria, Pretoria), Sue Atkins made an invaluable contribution to the development of lexicography in South Africa, in particular for Sepedi, Setswana, Sesotho, isiNdebele, isiZulu, Siswati, isiXhosa, Tshivenda and Xitsonga. As a result of these groundbreaking events and the subsequent widespread interest in designing and producing dictionaries for these languages, dictionary-making in South Africa has shifted from random, haphazard publications to a serious commitment to lexicographic principles and practice. More and more dictionaries of a high quality are now being produced in South Africa. Sue Atkins receives an honorary doctorate from the University of Pretoria for her outstanding achievements and contributions to international lexicography and lexicographic guidance to South Africans.

At the graduation ceremony, Atkins responded with the following speech of acknowledgement:

It is with the greatest pleasure, and a sense of deep humility, that I accept the honour you confer on me today, thus belying the words of our great predecessor in lexicography, Samuel Johnson, who said in the Preface to his splendid Dictionary of 1755:

It is the fate of those who toil at the lower employments of life ... to be exposed to censure, without hope of praise; to be punished for neglect, where success would have been without applause, and diligence without reward. Among these unhappy mortals is the writer of dictionaries ... Every other authour may aspire to praise; the lexicographer can only hope to escape reproach ...

I have believed this for over half a lifetime, and I am now in a state of shock. And yet I realise that this honour marks, not so much my own contribution to dictionary making, as the great surge in lexicographic activity and enthusiasm which has swept over South Africa during the past ten years. Your government is to be applauded for its far-sightedness in legislating for the nationwide dictionary-making initiative, and thus opening the way to all this exciting work that is happening around us here. It was, I know, thanks to these measures that your National Lexicographic Units (NLUs) were established, and I know, too, that one of the catalysts in this whole movement was the Department of African Languages in the University of Pretoria. It is an honour and a pleasure to be associated with this great institution. 
I first came to South Africa in 1997, to lead the SALEX (South African Lexicography) workshop, held at Rhodes University, Grahamstown, under the auspices of the Dictionary Unit for South African English, and organized by its Director. This first workshop lasted two weeks, and was attended by almost forty South African linguists, many of them distinguished scholars, and some already with considerable lexicographic experience. During these two weeks, we worked through the basics of dictionary editing, and the various language groups each produced one or two dictionary entries. These were entries for a monolingual dictionary. Bilingual dictionaries present different problems and require different training, as was realised by the linguists who founded AFRILEX, the African Association for Lexicography. And so the following year I returned to South Africa, this time to Pretoria, with my colleague Michael Rundell, to lead the AFRILEX-SALEX Workshop in bilingual dictionary-making, organized by Professor D.J. Prinsloo, of the Department of African Languages. This time, over fifty South African linguists spent two weeks learning the trade and writing entries from English into their own language. The most striking thing about these events was the extraordinary energy of the participants, and their unquenchable enthusiasm for everything lexicographic. The two Workshops, I believe, provided the basic training of the South African linguists who were subsequently to work on the various African language dictionaries in the newly-founded Dictionary Units, as well as those working in other lexicographic initiatives. I know that the University of Pretoria is proud to house the isiNdebele Unit, and a branch office of the Sepedi Unit.

Now I would like to mention the difference between dictionary writing as it used to be, and dictionary writing today. Until recently, lexicographers collected citations on index cards or in notebooks, and wrote dictionary entries on the basis of these notes together with what they knew about the word. With the advent of computers, however, came the text corpus. This is an electronic collection of texts, drawn from books, letters, newspapers, transcribed conversation and so on. These texts are selected and prepared for use by lexicographers, with software that allows us to look at thousands of instances of a word in real use, that is, as it is used by ordinary people in everyday life. Such a corpus takes us beyond what we as individuals know about the word, and we no longer have to rely solely on how we think the word is used. This is an invaluable tool for dictionary editors, and sometimes it is just plain fascinating as well. For instance, when I ask English speakers to give me an example of the use of the word ago, they will say 'fifty years ago' or 'a couple of days ago' or 'a long time ago'. Twenty-five years ago, when I first looked this word up in a corpus, I was delighted to find phrases like 'three ex-wives ago' and 'four gins and two martinis ago'. We would never have thought them up, yet we can all understand them. Seriously, however, nowadays most respectable dictionary projects start from an analysis of corpus data.

The first initiative in corpus building in South Africa came from the University of Pretoria. Already in 1989, the Department of African Languages had 
seen the start of corpus creation for the African languages spoken in South Africa, that is to say, Sepedi, Setswana, Sesotho, isiNdebele, isiZulu, Siswati, isiXhosa, Tshivenda and Xitsonga. This work received a great impetus with the advent of the National Lexicographic Units, who took the principled decision to consult text corpora for evidence on how the words of their language behave. Since then these corpora have also become the basis of lexicographic and linguistic research, the development of commercial spell-checkers, of part-ofspeech taggers, of lexicons for machine translation, and other similar applications. These South African corpora are mainly texts scanned from literary works, both prose and poetry, and also grammar books, newspapers and magazines. A start has been made on compiling 'oral corpora', which contain transcriptions of spontaneous and semi-scripted speech. These nine corpora range in size from 2 million to 11 million words and they continue to grow. This is a tremendous achievement for a single nation.

To set this achievement in context, the first British lexicographic corpus freely available to all researchers, the British National Corpus, took three years to complete, involved the collaboration of three major dictionary publishers, two universities and the British Library, and 15 years ago cost one million pounds, half of which came from the government. The American National Corpus, since its inception in 1999, has so far managed to collect and process only 22 million words of American English, despite its enormous geographical coverage, the many universities and publishers involved, and the very many works now available in electronic format, thanks to computer typesetting. When set against these facts, the South African corpus-building initiative is truly impressive.

The long-term goal of the legislation was the production of a monolingual dictionary in each of the nine African languages, and this objective lies at the heart of the academic work being carried out by Lexicographic Units all over the Republic of South Africa. Quite a number of basic monolingual dictionaries have been published, and some Units have also published bilingual dictionaries. The international Laurence Urdang Award to support lexicographic work, won by Professor Prinsloo and the Department of African Languages, was used to bring together the consultative body to establish the lexicographic needs of isiNdebele.

Other initiatives have arisen directly or indirectly out of the AFRILEXSALEX Workshop. Scholarly writings based on analyses of corpus data have established South Africa as a focus of lexicographic work in the eyes of the international research community, and this work continues to grow and involve a new generation of South African linguists. Bilingual dictionaries from English into local African languages, have begun to appear as commercial publications. An excellent software suite for the production of dictionaries, TshwaneLex, created and first trialled in South Africa, is now in use throughout the world. 
Despite this encouraging situation, many challenges still lie ahead. Unlike the major institutions in Europe and the U.S.A., with a long tradition of scholarly and historical lexicographic work on linguistic principles, the Dictionary Units for the African languages of South Africa have to build their own lexicographic tradition, and this is not something that can happen overnight, although the recent work by the members of AFRILEX has laid down a solid foundation on which to build your modern dictionaries. For this great lexicographic initiative to continue to grow, develop and prosper, there is a need for a united effort on the part of your institutions, including the University of Pretoria, to bring dictionaries to the forefront of linguists' concerns, so that not only university academics and researchers, but school teachers and students of all ages, may appreciate the new dictionaries and use them to the full. And, of course, continue to record and refine the account of the languages to be found in them.

To that end, I would urge you to focus on teaching dictionary skills to students at schools and universities (and perhaps to their teachers too); to encourage scientifically planned research into the use of dictionaries in schools, colleges, universities and the home; and to make your dictionaries as user-friendly as possible. Here I should stress my belief that if a careful student makes a mistake when using his/her dictionary, then in most cases that is the fault of the dictionary not the student. A dictionary is a dialogue between the lexicographer and the dictionary user. We can write clear, accurate and helpful entries that suit our target readership without lowering lexicographic standards. This practice is already firmly established in South Africa: long may it prosper! 